\title{
Rate and temperature effects on the fracture toughness of a rubber-modified epoxy
}

\author{
B. J. Cardwell and A. F. Yee* \\ Department of Materials Science and Engineering, University of Michigan, Ann Arbor, MI \\ 48109, USA \\ (Received 26 February 1992; revised 1 July 1992)
}

\begin{abstract}
A series of three-point bend fracture toughness tests was performed at various loading rates and temperatures on both rubber-modified and unmodified epoxy specimens. The fracture toughness of the modified samples was determined to be rate- and temperature-dependent. Using time-temperature superposition, an apparent activation energy was determined by shifting the fracture toughness data along the rate axis for each temperature tested. Surprisingly, this apparent activation energy calculated for the rubber-modified epoxy was found to be within $2 \%$ of the value of the activation energy determined for the $\beta$ relaxation peak found from small strain d.m.a. measurements of the unmodified epoxy matrix. This was an unexpected yet interesting correlation. Since shear yielding is the primary mechanism by which this epoxy system is toughened, it can be hypothesized the $\beta$ relaxation may significantly influence the kinetics of yielding and consequently the fracture tougness of the material. Plastic zone geometry and fracture mechanisms were investigated and were found to support this hypothesis.
\end{abstract}

(Keywords: epoxy resin; fracture toughness; temperature effects; rubber-modified epoxy; time-temperature superposition; $\beta$ relaxation)

\section{INTRODUCTION}

Epoxy resins are used in a wide range of modern structural components, especially as the matrix of many high-strength fibre-reinforced composites found in the aerospace industry. Although these epoxies possess a number of advantages, such materials are usually inherently brittle. A good way to increase fracture resistance of these materials is to make additions of rubber as a dispersed secondary phase. Our research group $^{1-4}$ and others ${ }^{5-7}$ have been investigating the nature of the mechanisms by which the secondary rubber phase toughens an epoxy matrix. One such mechanism by which certain epoxy-rubber systems are toughened is the cavitation of the rubber particles followed by shear yielding of the epoxy ahead of a crack tip ${ }^{2}$. Yet, little is known about the influence of temperature and the rate of deformation on materials toughened by this mechanism. A better understanding of how particular fracture mechanisms are affected by temperature and rate is needed to enhance the ability to tailor new and modify existing high performance materials. This is the primary motivation for the work reported here. In the following, we present the effects of rate and temperature on the toughness of a model methacrylate-butadiene-styrene (MBS) modified epoxy. It turns out that the toughness data can be correlated with the $\beta$ relaxation of the matrix. The reason for the correlation is that the toughness is mainly due to shear yielding, kinetics of which is controlled by the $\beta$ relaxation. Details of our investigation are presented in the following.

\footnotetext{
* To whom correspondence should be addressed
}

\section{EXPERIMENTAL DETAILS}

\section{Materials}

The epoxy resin used for all the specimens was $\operatorname{DER}^{\circledR}{ }^{\circledR} 331$, which is a derivative of a diglycidyl ether of bisphenol A (DGEBA). The epoxy resin monomers can be represented by the chemical structure:

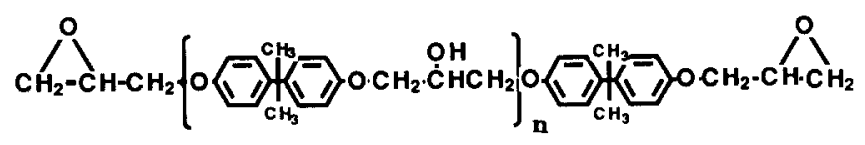

where $n$ is approximately equal to 0.1 . This resin has an average molecular weight of $376 \mathrm{gmol}^{-1}$. The curing agent used was piperidine.

The rubber modifier is manufactured and distributed by the Rohm and Haas company under the trade name of Paraloid ${ }^{\circledR}$ EXL-2691, formerly known as Acryloid $^{\circledR}$ KM-653. The modifier exists as a $0.3 \mu \mathrm{m}$ preformed core-shell MBS rubber particle. The core is primarily a poly(butadiene)-styrene rubber which is surrounded by a mainly poly(methyl methacrylate) shell. The glass transition temperature $\left(T_{\mathrm{g}}\right)$ of the rubbery core is approximately $-80^{\circ} \mathrm{C}$. The rubber-modified samples used in this study contained 5 p.h.r. (parts per hundred resin by weight) of these modifying rubber particles. Table $l$ describes the composition of the test samples.

To prepare the modified specimens, the epoxy was first heated to $110^{\circ} \mathrm{C}$ to lower the viscosity of the resin, making it easier to disperse the rubber particles. The preformed rubber particles were then added slowly and blended in by hand. The mixture was next held under a vacuum and mechanically stirred for $10 \mathrm{~min}$ to disperse the particles 
Table 1 Sample compositions

\begin{tabular}{llll}
\hline & $\begin{array}{l}\text { Epoxy resin } \\
(\mathrm{phr})\end{array}$ & $\begin{array}{l}\text { Piperidine } \\
(\mathrm{phr})\end{array}$ & $\begin{array}{l}\text { EXL-2691 } \\
(\mathrm{phr})\end{array}$ \\
\hline $\begin{array}{l}\text { Rubber modified } \\
\text { Unmodified }\end{array}$ & 100 & 5 & 5 \\
& 100 & 5 & 0 \\
\hline
\end{tabular}

and degas the resin. The piperidine curing agent was then added, and the mixture was stirred for another $5 \mathrm{~min}$. The epoxy was then poured into a preheated mould and cured at $120^{\circ} \mathrm{C}$ for $16 \mathrm{~h}$. The unmodified specimens were prepared in the same manner, but without the rubber particle addition. Test specimens were machined from these prepared plaques.

The $T_{\mathrm{g}}$ of the cured DGEBA resin was measured using a Perkin-Elmer series 7 differential scanning calorimeter, and its onset was $89 \pm 2^{\circ} \mathrm{C}$. The morphology of a fracture surface was characterized using a scanning electron microscope (SEM). The SEM revealed the particles were not uniformly distributed in a completely random fashion throughout the epoxy matrix. Some particle agglomeration existed which could not be eliminated through vigorous mechanical dispersion.

\section{Fracture toughness measurements}

Fracture toughness measurements were conducted using a pre-cracked specimen in a three-point bending configuration. Three-point bend (3PB-SEN) specimens were machined to dimensions of $127 \times 12.7 \times 6.35 \mathrm{~mm}$. A small, $1.5 \mathrm{~mm}$ deep notch was first cut into the centre of the sample using a jeweller's saw. A fresh razor blade, which had been chilled in liquid nitrogen, was then tapped into the cut with a hammer to create a pre-crack in the specimens. The samples which were tested contained pre-cracks which were a minimum of $3.8 \mathrm{~mm}$ and a maximum of $7.6 \mathrm{~mm}$ in length. These samples were then loaded in a three-point bend configuration using a servo-hydraulic Instron testing machine. Crosshead speed was varied to produce the different three-point bend test rates. The test temperature was controlled using an isothermal test chamber affixed to the testing machine. The span width of the three-point bend apparatus was $101.6 \mathrm{~mm}$.

Assuming linear elastic fracture mechanics apply, the outer fibre stress, $\sigma_{\max }$, at the crack tip can be calculated as:

$$
\sigma_{\max }=\frac{3 S}{2 B W^{2}} F_{\max }
$$

where $F_{\max }$ is the maximum value of force required for fracture (N), $B$ is the specimen thickness $(\mathrm{m}), W$ is the specimen width $(\mathrm{m})$ and $S$ is the span $(\mathrm{m})$.

For this specimen geometry, the geometry factor, $Y$, can be determined by the equation ${ }^{8}$ :

$$
\begin{aligned}
Y= & 1.96-2.75(a / W)+13.66(a / W)^{2}-23.98(a / W)^{3} \\
& +25.22(a / W)^{4}
\end{aligned}
$$

where $a$ is the crack length (m).

The critical value of the stress intensity factor, $K_{\mathrm{IC}}$, can be calculated using the equation:

$$
K_{\mathrm{IC}}=Y \sigma_{\max }(a)^{0.5}
$$

Study of the process zone

The effects of test rate and temperature on the materials were examined at the crack tip with both samples which were critically and sub-critically loaded.

Sub-critically loaded cracks were obtained by using a double side notch specimen in four-point bending, 4PB-DSN. This method is described in detail by Sue et $a l .{ }^{1}$. Ideally, this method produces a crack which has been loaded to the brink of failure. To produce such a sub-critically loaded crack, two nearly identical cracks are made on the same edge of a specimen. The sample is then loaded in the four-point bend configuration until one of the cracks has failed. The failure of one crack instantly relieves the loading at the tip of the other crack which has undergone some growth. The sub-critically loaded crack tip can now reveal the structure of the process zone just before failure. The toughening mechanism can then be probed using various microscopy techniques. This method was used to produce a process zone at the crack tip under the various testing conditions. Petrographic thin sections were made at the test sample's mid-plane, and the process zone could be observed using transmitted light microscopy.

Fracture surfaces were observed using both optical and electron microscopy techniques. These postmortem microscopy samples were obtained from the remnants of three-point bend fracture specimens. A low power stereo microscope was used for the macroscopic observations of the fracture surface, while other optical microscopy was performed using a Nikon Optiphot transmitted light microscope. Electron microscopy samples were first sputtered very lightly with gold-palladium and then observed in a Hitachi S-800 SEM at $2 \mathrm{kV}$ accelerating voltage.

\section{Dynamic mechanical experiments}

D.m.a. were performed using a DuPont 983 dynamic mechanical analyser. Samples of the unmodified epoxy were cut to $75 \times 12.8 \times 3 \mathrm{~mm}$ for dynamic mechanical testing. Samples were tested over various temperature ranges between $-150^{\circ} \mathrm{C}$ and $120^{\circ} \mathrm{C}$ in steps of $5^{\circ} \mathrm{C}$. The heating rate between intervals was $5^{\circ} \mathrm{C} \mathrm{min}^{-1}$, and the chamber was allowed to equilibrate at each temperature for $5 \mathrm{~min}$. Five frequencies $(0.1,0.32,1.0,3.2$ and $8.0 \mathrm{~Hz}$ ) were used to probe the dynamic response of the samples. The samples were tested at a constant small strain amplitude of $0.67 \mathrm{~mm}$. The results of the d.m.a. experiments were shifted using the DuPont Superposition version 4.1B software package.

\section{RESULTS AND DISCUSSION}

\section{Fracture toughness measurements}

For the rubber-modified epoxy samples, the test temperature was limited to a maximum of $40^{\circ} \mathrm{C}$ and the test rate was limited to a minimum of 0.005 in s$^{-1}\left(1 \mathrm{in} \mathrm{s}^{-1} \equiv 25.4 \mathrm{~mm} \mathrm{~s}^{-1}\right)$. This was done in an attempt to keep the fracture of the three-point bend specimens in the unstable crack propagation mode, so the assumptions of linear elastic fracture mechanics would hold. Above the maximum temperature and/or below the minimum test rate, samples would either give a non-linear load-displacement curve or the crack would grow in a stable manner. Deviation from a linear load-displacement curve is due to the geometry of the 


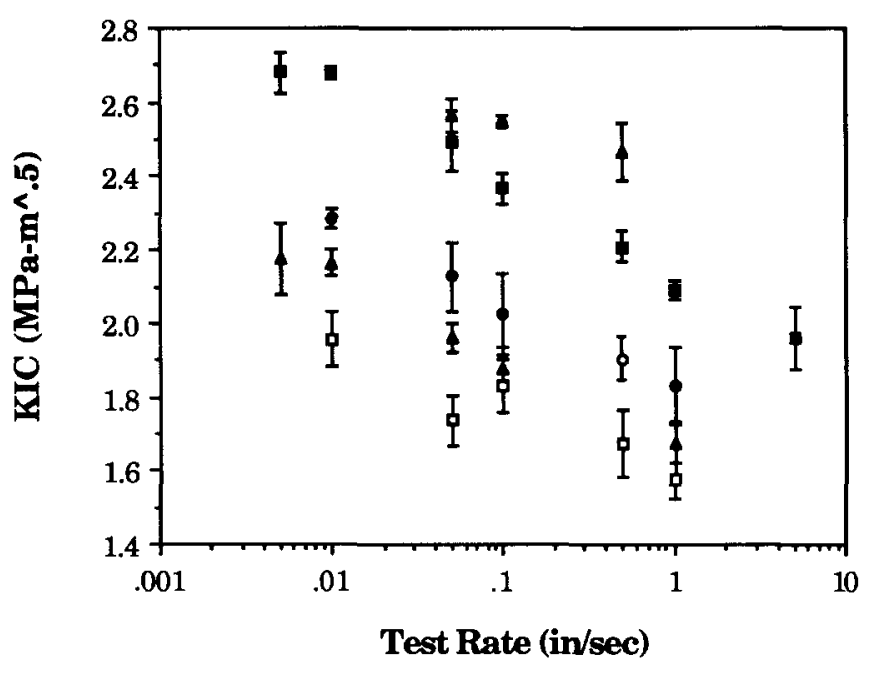

Figure 1 Fracture toughness data for DER $331+5 \%$ EXL-2691 versus test rate at various temperatures: $(\triangle) 40^{\circ} \mathrm{C} ;(\mathbb{\square}) 25^{\circ} \mathrm{C} ;(\mathrm{O}) 15^{\circ} \mathrm{C}$ : (A) $0{ }^{\circ} \mathrm{C} ;(\square)-15^{\circ} \mathrm{C}$

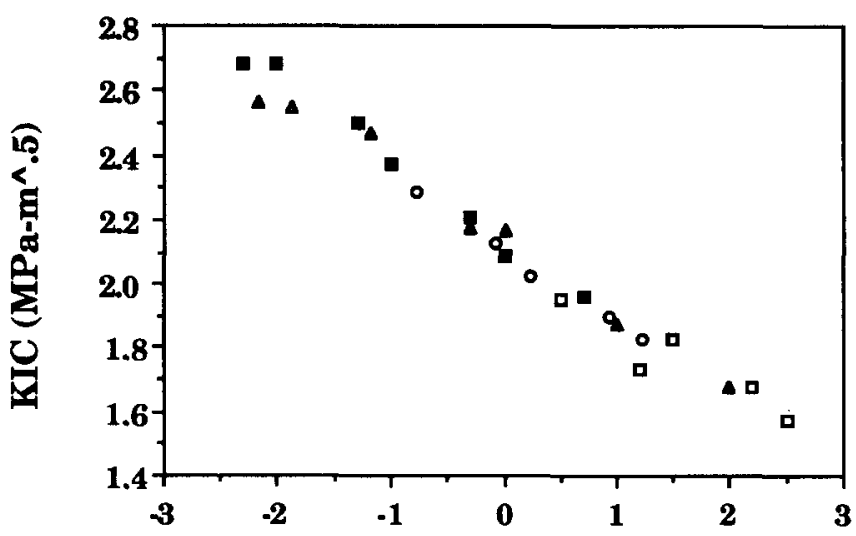

\section{Log[Test Rate (in/sec)]}

Figure 2 Shifted fracture toughness data for DER $331+5 \%$ EXL-2691. Curve shifted to master temperature of $25^{\circ} \mathrm{C}$. ( $\left.\triangle\right) 40^{\circ} \mathrm{C}$; (品) $25^{\circ} \mathrm{C} ;(\mathrm{O}) 15 \mathrm{C} ;(\Delta) 0^{\circ} \mathrm{C} ;(\square)-15^{\circ} \mathrm{C}$

SEN specimen in conjunction with the great increase in matrix ductility attributed to the proximity of the glass transition at around $89^{\circ} \mathrm{C}$.

The fracture toughness results for the rubber-modified epoxy, which were gathered at various test rates and temperatures, are shown in Figure 1. Using the time-temperature superposition principle, a master curve was constructed from these fracture toughness data using $25^{\circ} \mathrm{C}$ as the reference temperature, Figure 2. A plot of the shift factors obtained in this construction plotted against $1 / T$ can be found in Figure 3. The data fall approximately on a straight line. When these data are fitted to an Arrhenius type equation, an apparent activation energy of $22.9 \mathrm{kcal} \mathrm{mol}^{-1}$ was found for the toughening process.

When the fracture toughness of the unmodified epoxy samples is determined over the same ranges of temperature and test rate, it is found they do not have the same rate and temperature dependence. The unmodified specimens have a relatively constant resistance to fracture, within the scatter of the measurements, over the range tested. The unmodified samples have a fracture toughness of approximately $0.8 \pm 0.1 \mathrm{MPa} \mathrm{m}^{1 / 2}$

\section{Study of the process zone}

When examining the fracture surfaces of the unmodified samples, no distinct features could be observed in optical or electron microscopy. The 3PB-SEN and 4PB-DSN samples of the unmodified epoxy also showed no substantial birefringence in crossed polarized light which indicates an absence of significant amounts of plastic deformation.

Visual observation and optical microscopy of the fracture surface of the modified epoxy revealed the existence of a stress-whitened zone ahead of the pre-crack region. The width of this zone increased with increasing fracture toughness in the samples. SEM micrographs of this stress-whitened zone appear as a region of particle cavitation and matrix ductility (Figure 4 ) when compared

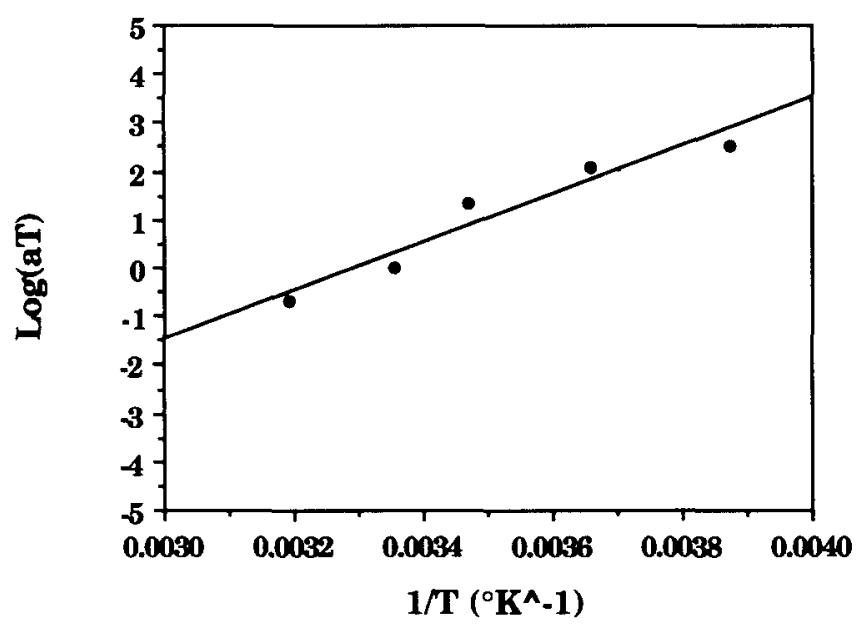

Figure 3 Plot of shift factor, $\log \left(a_{r}\right)$, versus $1 / T$ for the shifted fracture toughness data for DER $331+5 \%$ EXL-2691. $E_{a}=22.9 \mathrm{kcal} \mathrm{mol}^{-1}$

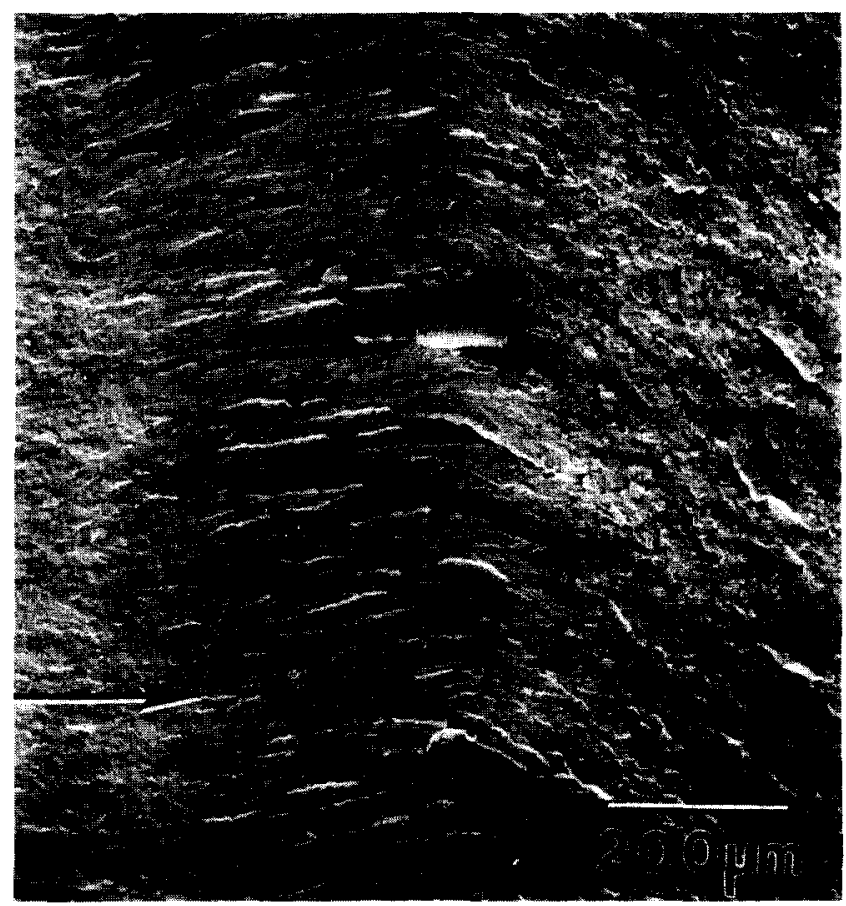

Figure 4 SEM micrograph of DER $331+5 \%$ EXL-2691 fracture surface showing matrix ductility. Arrow indicates crack propagation direction 

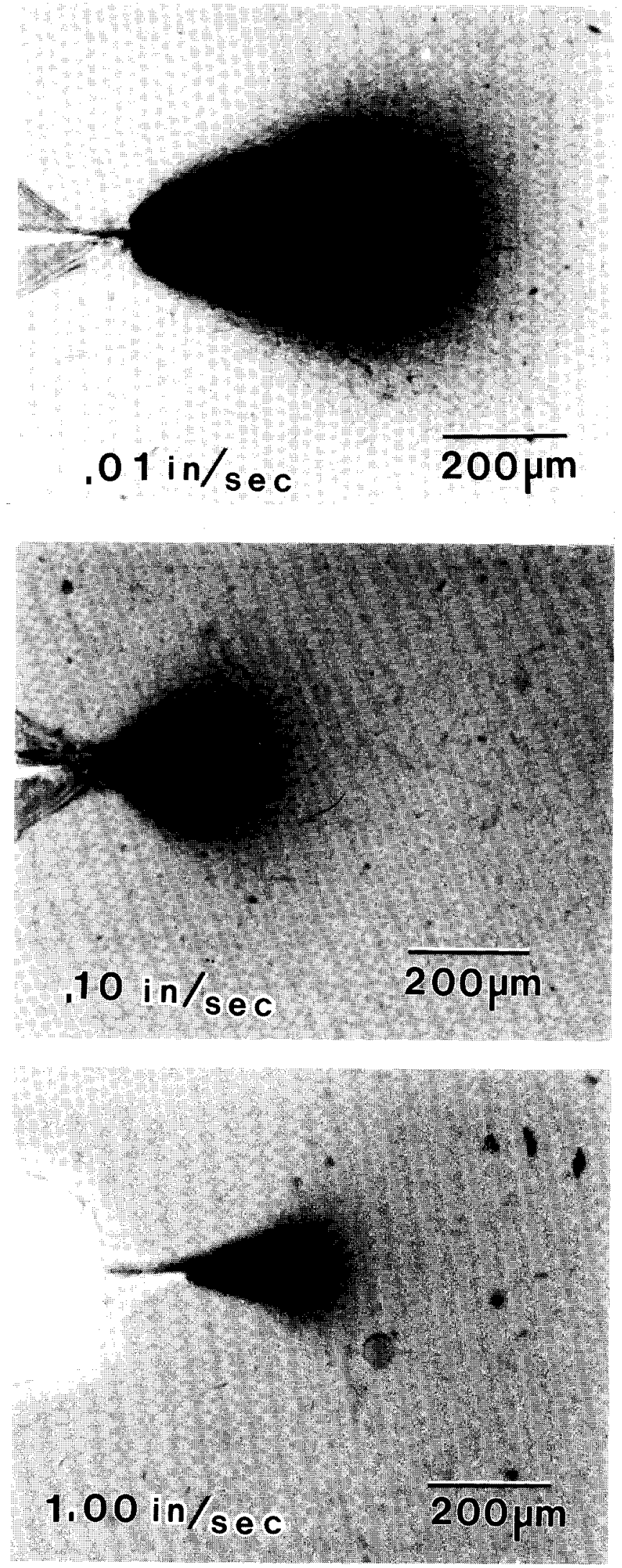

with the almost featureless surface of the unmodified epoxy samples.

When the petrographic thin sections obtained by using the 4PB-DSN method are observed in Figure 5, we found a region of cavitation and plastic yielding ahead of the sub-critically loaded crack tip. The cavitated area appears as a darkened zone at the crack tip. When this zone is
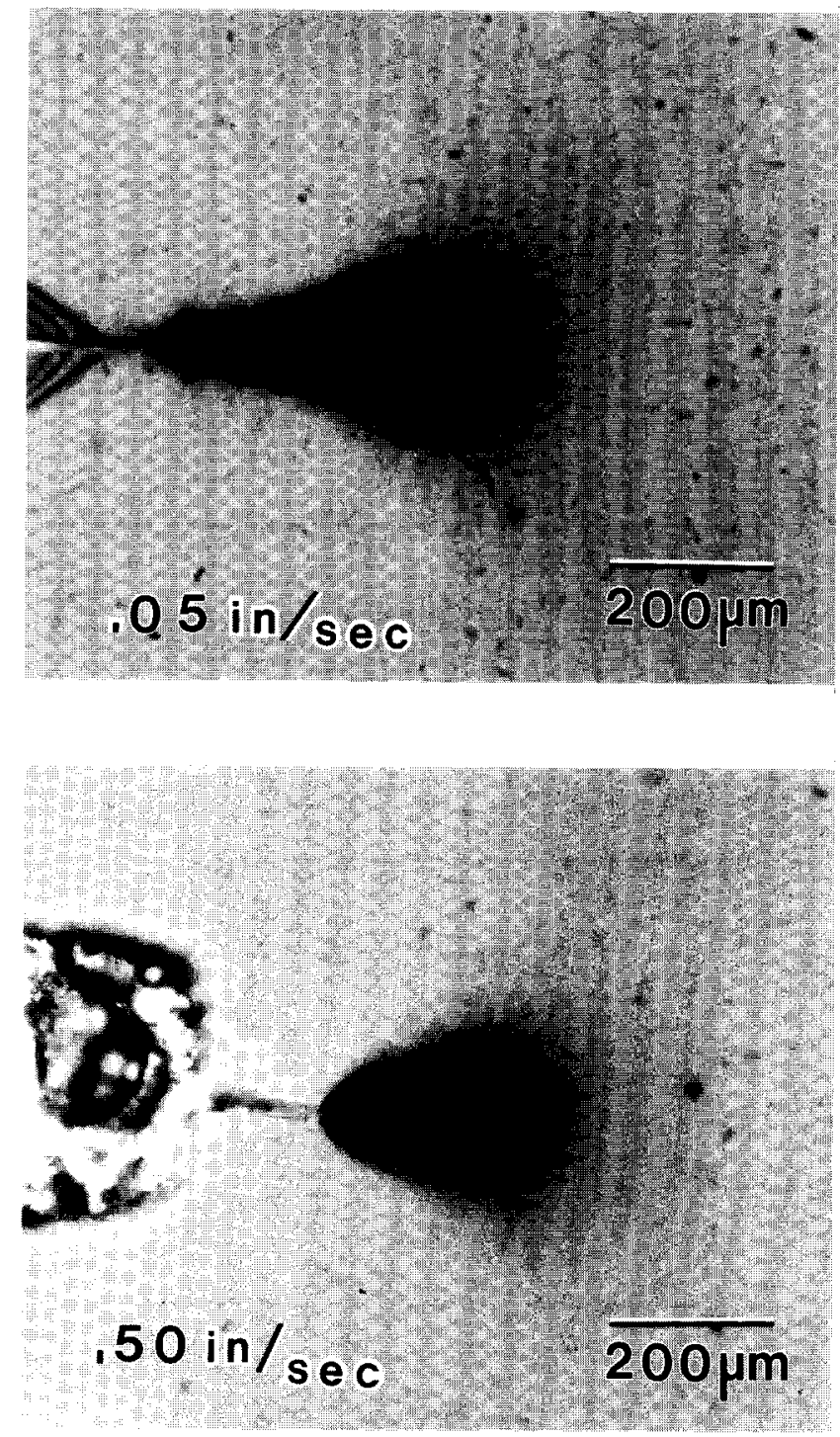

Figure 5 Micrographs of the crack tip process zone of the 4PB-DSN samples at various testing conditions

observed through cross-polarized light, as shown in Figure 6, it is apparent from the birefringence that there exists a zone of plastic deformation which is completely embedded inside the cavitation zone. It should be noted that the shear yielded zone is difficult to discern due to the scattering of light caused by the cavitated particles. The size of this zone increases when the samples are 


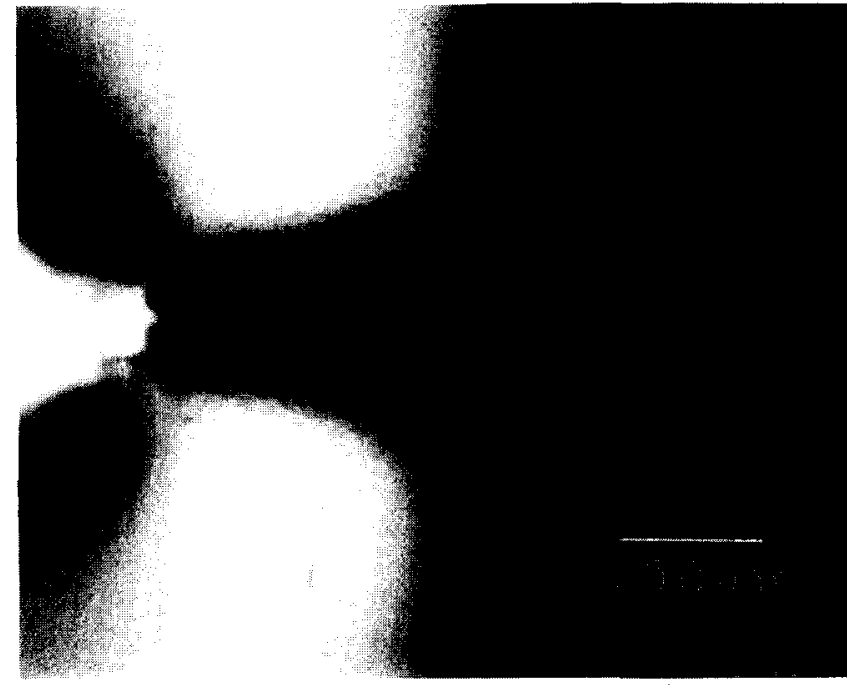

Figure 6 Optical micrograph of process zone taken between cross polarizing filters

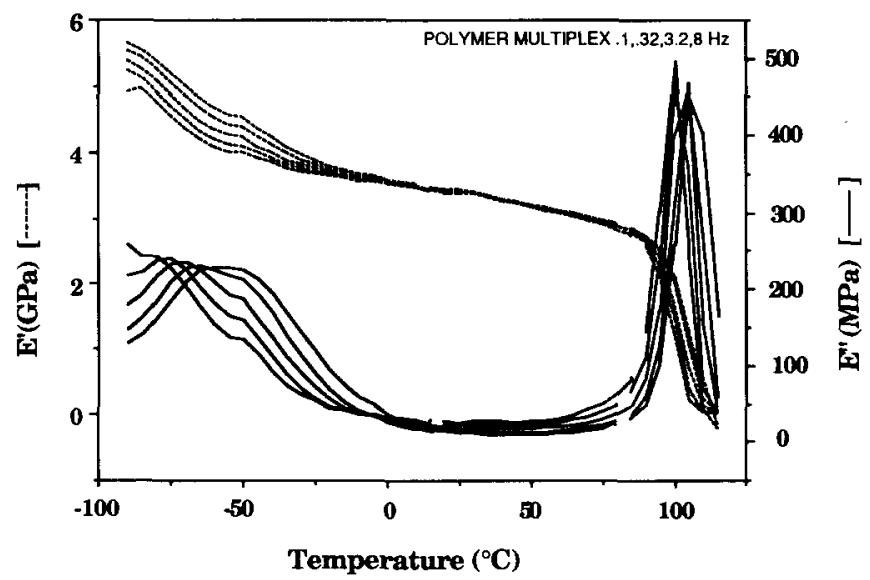

Figure 7 D.m.a. spectra gathered for DER 331 cured with piperidine

exposed to testing conditions which cause a rise in the fracture toughness of the materials (i.e. decreased test rate or increased test temperature).

\section{Dynamic mechanical experiments}

The d.m.a. spectra in Figure 7 show a major relaxation around $89^{\circ} \mathrm{C}$ at $1 \mathrm{~Hz}$. A broader, less pronounced $\beta$ relaxation peak is also seen centred near $-60^{\circ} \mathrm{C}$. From d.m.a. results determined at various excitation frequencies at temperatures between $-100^{\circ} \mathrm{C}$ and $-20^{\circ} \mathrm{C}$, it was possible to construct a master curve around $-60^{\circ} \mathrm{C}$. This master curve is shown in Figure 8 . The shift factors, $a_{T}$, used for the construction of the master curve are plotted against the reciprocal of temperature in Figure 9. When these data were fit to an Arrhenius type relationship, an apparent activation energy of $22.5 \mathrm{kcal} \mathrm{mol}^{-1}$ was calculated for the $\beta$ relaxation process. The nature of the molecular motion giving rise to this relaxation process remains unclear. Some researchers, for example Takahama and $\mathrm{Geil}^{9}$, consider it to arise from the motion of the hydroxyether groups. Others ${ }^{10}$ consider it to be at least partly due to the motion of the bisphenol A unit. It is beyond the scope of this work to attempt to clarify this ambiguity. For now, only an empirical correlation is sought between the fracture toughness and the $\beta$ relaxation.

\section{DISCUSSION}

Other researchers have examined the effects of temperature and rate on the fracture properties of epoxy. Hunston and coworkers ${ }^{5}$ investigated the effect of rate and temperature on the fracture behaviour of adhesive joints and found there existed a relationship which made the use of time-temperature superposition valid. However, the effect of these variables on the fracture mechanism was not clearly delineated by them. Scott et al. ${ }^{6}$ have also investigated the temperature effect, but their observations were limited to macroscopic descriptions of the fracture behaviour.

Mai and Low ${ }^{7}$ have attributed the change in fracture toughness in modified and unmodified epoxies to a thermal blunting of the crack tip, while Yee and coworkers $^{2}$ attribute the increase in fracture toughness in the rubber-modified system to a plastic dilation and shear yielding of the matrix following the cavitation of rubber particles. The effect of temperature on the fracture toughness of cured epoxy samples was documented by Ochi et al. ${ }^{11}$. They concluded that the presence of low temperature mechanical relaxation increased the fracture toughness of their epoxy samples at temperatures above the relaxation temperature. The change in fracture behaviour of their samples was attributed to an increase of ductility due to the presence of the low temperature relaxation. However, their investigation

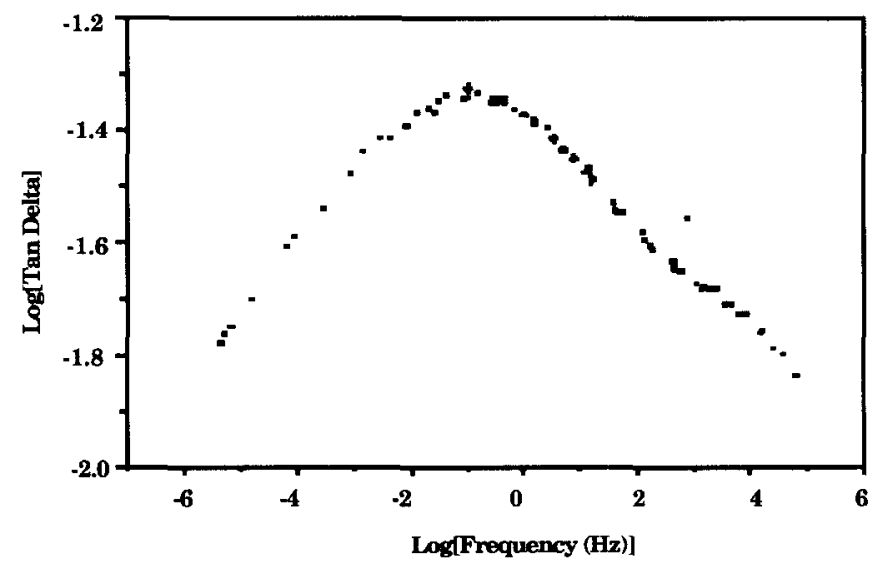

Figure 8 Master curve constructed from tan delta data gathered around the $\beta$ relaxation peak of DER 331 cured with piperidine

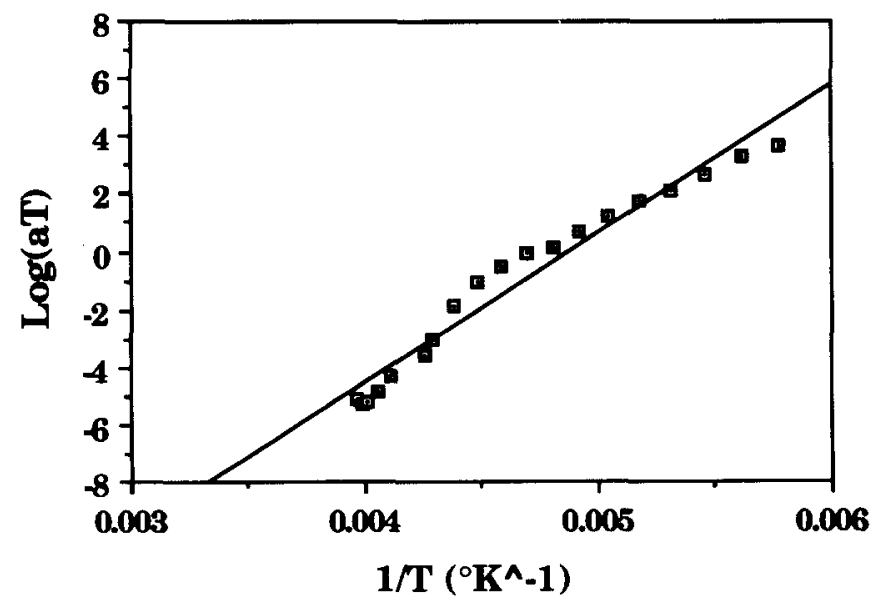

Figure 9 Plot of shift factor, $\log \left(a_{T}\right)$, versus $1 / T$ for the shifted tan delta data gathered around the $\beta$ relaxation peak of DER 331 cured with piperidine. $E_{\mathrm{a}}=22.5 \mathrm{kcal} \mathrm{mol}^{-1}$ 
only qualitatively demonstrated the possible connection between the presence of a low temperature relaxation and an increase in matrix ductility. One objective in investigating the effects of test rates and temperatures on the material's fracture toughness was to determine if some sort of relationship existed between the experimental parameters and the fracture toughness; and if so, ascertain what these relationships were.

The fracture toughness of both rubber-modified and unmodified epoxy samples was quantified using standard fracture mechanics techniques to determine the critical stress intensity factor, $K_{\mathrm{IC}}$. The $K_{\mathrm{IC}}$ data from Figure 1 were shifted to an arbitrary master temperature of $25^{\circ} \mathrm{C}$ in Figure 2. An Arrhenius relationship was the best fit for the shift factors giving an activation energy of $22.9 \mathrm{kcal} \mathrm{mol}^{-1}$ for the process. This activation energy is very close to the $22.5 \mathrm{kcal} \mathrm{mol}^{-1}$ activation energy found for the $\beta$ relaxation of the epoxy determined from dynamic mechanical techniques. This information would seem to suggest that there could exist a relationship between the low temperature $\beta$ relaxation process in the epoxy matrix and the toughening processes which occur during the fracture of this material system. Experiments were then performed to probe the toughening mechanism to investigate possible connections.

The fracture toughness of the rubber-modified epoxy specimens increases with decreasing test rate and increasing test temperature. The increase in toughness in these samples is accompanied by an increase in the size of the process zone ahead of the crack tip (Figure 5). This process zone consists of the cavitated rubber particles and plastic dilatation of both the cavities and the surrounding matrix as well as induced shear yielding in the epoxy matrix ${ }^{2}$.

The unmodified epoxy samples showed little or no plastically deformed zone ahead of the crack tip. The fracture toughness of these samples also showed no significant dependence on the test rate or temperature. The unmodified epoxy is inherently brittle in the SEN configuration and the rubber modifiers are needed to induce the shear yielding necessary for an increase in toughness. The role of rubber particles in the modified epoxy is to cavitate and change the tri-axial stress state ahead of the crack tip ${ }^{2}$. This change in stress state creates an environment in which substantial amounts of shear yielding can occur. Without the presence of rubber particles, the amount of shear yielding is insignificant.

We now consider both the rubber modifier and the epoxy matrix as the possible origin of the rate dependence in the rubber-modified samples. The $T_{\mathrm{g}}$ of the poly(butadiene) rubber core of the modifying particles is around $-80^{\circ} \mathrm{C}$. This is well below the lowest temperature used in this investigation, suggesting the mechanical properties of the rubber may be considered as constants over the ranges of rate and temperature which were investigated. If the $T_{\mathrm{g}}$ were to lie close to the test temperature, the rubber particles may exhibit an increase in their resistance to cavitation under a tri-axial stress. An increase in cavitational resistance leads to a reduction in the quantity of cavitating rubber particles; hence, there is a reduction in the amount of shear deformation formed and the overall fracture toughness of the material is lowered ${ }^{3}$. If the rate and temperature dependence of the fracture toughness is not directly due to changes in the rubber particle, then it is likely to be related to the deformation of the matrix. The unmodified samples lack a temperature and rate dependence. These unmodified samples also show an absence of plastic deformation at their crack tips. Only the rubber-modified samples showed both a rate and temperature dependence with the presence of plastic deformation. This suggests the rate and temperature dependence in the rubbermodified samples may arise from the shear yielding process in the epoxy matrix. To further support this assumption, data were obtained from previous work by Pearson and $\mathrm{Yee}^{4}$ for the uniaxial tensile behaviour of a similar rubber-modified epoxy at various test rates and temperatures. Epon 828, a DGEBA epoxy which is of nearly identical composition as the resin used in these experiments, was modified with $20 \%$ of carboxylterminated butadiene-nitrile (CTBN) rubber. The curing agent and cure schedule are also identical to those used in this work. The uniaxial yield behaviour of this material was examined at various strain rates at $-16^{\circ} \mathrm{C}$ and $25^{\circ} \mathrm{C}$. When these data were compiled and examined, the yield stress showed a definite rate and temperature dependence. The activation energy of $22.9 \mathrm{kcal} \mathrm{mol}^{-1}$, determined from the fracture toughness measurements obtained in this investigation, was used to shift the low temperature data from Pearson and Yee's experiments. In Figure 10 one can see that by shifting the tensile data using the activation energies found from the toughness data in our investigation, the $-16^{\circ} \mathrm{C}$ and $25^{\circ} \mathrm{C}$ data now lie on approximately a straight line. This strongly indicates that the two types of deformation have the same activation energy. To be more conclusive, the yield stress data would have to be obtained for more temperatures and strain rates. This was omitted in the present study since the agreement is quite satisfactory.

The good correlation between the activation energy of the toughening process with the activation energy of the $\beta$ relaxation process in the matrix allows us to hypothesize that the $\beta$ relaxation significantly influences the kinetics of the shear yielding process, and consequently the fracture toughness of the material system.

\section{CONCLUSIONS}

The effects of rate and temperature on the fracture toughness of unmodified and rubber-modified DGEBA

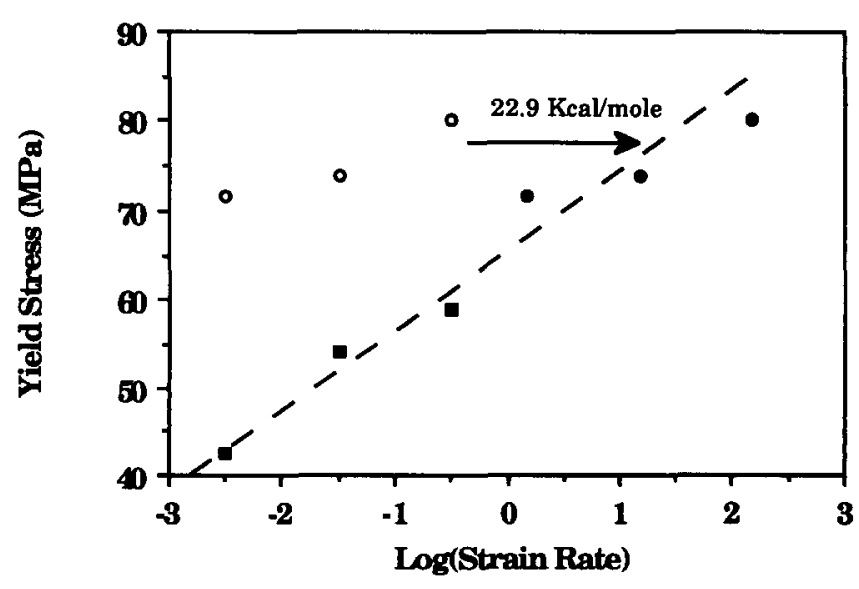

Figure 10 Plot of yield stress versus strain rate at two different temperatures for piperidine-cured Epon 828 , modified with a CTBN rubber. The data gathered at $-16^{\circ} \mathrm{C}$ were shifted by $22.9 \mathrm{kcal} \mathrm{mol}^{-1}$ to determine if the yield data shifted to a common line. (a) $25^{\circ} \mathrm{C}$; (O) $-16^{\circ} \mathrm{C}$; (O) shifted $-16^{\circ} \mathrm{C}$ 
epoxy specimens was investigated using a series of three-point bend specimens.

Over the test rate and temperature ranges tested, the unmodified epoxy showed no strong dependence on the testing conditions, while the rubber-modified samples showed an increase in fracture toughness with a decrease in testing rate or an increase in temperature. The increase of fracture toughness was also accompanied by an increase of shear plasticity found at the crack tip.

By shifting the fracture toughness data to a master curve and employing the time-temperature superposition principle, an apparent activation energy for the toughening process was determined to be $22.9 \mathrm{kcal} \mathrm{mol}^{-1}$. Through dynamic mechanical experiments, the activation energy for the $\beta$ relaxation process of the epoxy matrix was found to be $22.5 \mathrm{kcal} \mathrm{mol}^{-1}$. Using data obtained from Pearson and $\mathrm{Yee}^{4}$ of uniaxial tensile tests on an epoxy system with an identical matrix, it was found the yield stress data was also time- and temperature-dependent. When the activation energy found from fracture toughness measurements was applied to this yield stress data using an Arrhenius type relationship, the sets of yield stress data collected at two temperatures shifted to a common line. This information supports the assumption that yielding process in the epoxy matrix determines the time and temperature dependence of its toughness.

\section{ACKNOWLEDGEMENTS}

This work was supported by a Materials Research Group grant from the National Science Foundation (DMS8708405). Brian Cardwell was partially supported by a supplemental Research Experience for Undergraduates grant in the MRG. The authors would like to thank Dr Raymond A. Pearson for his assistance and helpful discussions.

\section{REFERENCES}

1 Sue, H. J., Pearson, R. A., Parker, D. S., Huang, J. and Yee, A. F. Polym. Prepr. ACS, Div. Polym. Chem. 1988, 29, 147

2 Pearson, R. A. and Yee, A. F. J. Mater. Sci. 1986, 21, 2475

3 Li, D., Yee, A. F. and Takahashi, K. ANTEC Proceedings for the Society of Plastics Engineers, Detroit, MI, 4-8 May 1992 , p. 1677

4 Pearson, R. A. and Yee, A. F. 'Toughening Mechanism in Elastomer-Modified Epoxy Resins', NASA Report, Contract NAS1-16132, October 1981

5 Hunston, D. L., Kinloch, A. J., Shaw, S. J. and Wang, S. S. 'Adhesive Joints' (Ed. K. L. Mittal). Plenum Press, New York, 1984, p. 789

6 Scott, J. M., Wells, G. M. and Phillips, D. C. J. Mater. Sci. 1980 15,1436

7 It Meng Low and Yiu Wing Mai J. Mater. Sci. 1989, 24, 1634

8 Brown, W. F. and Srawley, J. E. ASTM STP 410, American Society for Testing and Materials, Philadelphia, 1966

9 Takahama, T. and Geil, P. H. J. Polym. Sci., Polym. Phys. Edn 1982, 20, 1979

10 Yee, A. F. Polym. Prepr. ACS, Div. Polym. Chem. 1981, 22 (2), 285

11 Ochi, M., Shiba, T., Takeuchi, H., Yoshizumi, M. and Shimbo, M. Polymer 1989, 30, 1079 